
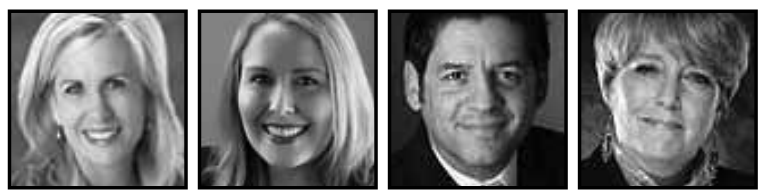

\title{
An Honest Account of the Humbling Experience of Learning to Teach Online
}

\author{
Kimberly Ferrario, Corinne Hyde, Brandon Martinez, \\ and Melora Sundt, University of Southern California
}

\section{ABSTRACT}

The focus of this article is on lessons learned about teaching through the online environment from the experience of $120+$ instructors who transitioned from teaching in a traditional face-to-face environment to a blended synchronous and asynchronous online world. We admit that we entered the synchronous virtual world with faulty assumptions and misplaced confidence, believing that what worked in the brick-andmortar world should also work, with little adaptation, in the virtual world. There continues to be so little literature about teaching in the synchronous virtual environment that we had to rely on our ability to learn quickly by trial and error.

\section{Introduction}

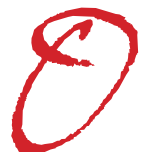

nline instruction is gaining momentum. As of 2008, more than 1 million $\mathrm{K}-12$ students were estimated to be enrolled in at least one online course, a $47 \%$ increase from two years earlier (Picciano \& Seaman, 2008). We see similar momentum in higher education: the 2011 Babson Survey (Allen \& Seaman, 2011) found that 6 million students - one third of all students enrolled in higher education-took at least one course online, an enrollment increase of $10 \%$ over the previous year, well above the $1 \%$ increase in higher education enrollments overall for the same period.

Teachers and administrators could perhaps have ignored these trends until the U.S. Department of Education (2010) reported that "students in online learning 
conditions performed modestly better, on average, than those learning the same material through traditional face-to-face instruction," (Evaluation of Evidence-Based Practices in Online Learning, p. ix). Along with this finding, the USDOE reported, "Instruction combining online and face-to-face elements had a larger advantage relative to purely face-to-face instruction than did purely online instruction" (p.xv).

Given the growth of online learning environments, we focus in this article on lessons learned about teaching through the online environment from the experience of $120+$ instructors who transitioned from teaching in a traditional face-to-face environment to a blended synchronous and asynchronous online world. We admit that we entered the synchronous virtual world with faulty assumptions and misplaced confidence, believing that what worked in the brick-and-mortar world should also work, with little adaptation, in the virtual world. There was so little (and there continues to be so little) literature about teaching in the synchronous virtual environment that we had to rely on our ability to learn quickly, as we did not want our students to suffer because of our ignorance. The purpose of this article is to share where we "skinned our knees" as we learned to ride this bicycle of the virtual world, in the hopes of assisting other teachers, and in the hopes of expanding our collective understanding of what it means to teach effectively.

\section{What Is a Virtual Classroom Like?}

Often the discussion of online versus face-to-face learning gets positioned as "asynchronous" versus "synchronous," as if online learning had no synchronous elements to it. Typically, "asynchronous" describes students accessing a website and completing assignments on their own time (Anderson, Rourke, Garrison, \& Archer, 2001). Our faculty has spent the past four years teaching more than 750 courses in an online environment that does both-provides virtual (i.e., online) face-to-face classes and supplements that learning with asynchronous experiences and resources. We are pleased to note that comparisons of student work produced in our online and our traditional brick-and-mortar programs have found no difference in overall student performance. The one big difference between the two groups is that the online students leave our program feeling more confident about using technology in their own instruction (Chong, 2012).

In this virtual classroom, video conferencing software (such as Adobe Connect, Blackboard Collaborate, or Cisco WebEx) is used as the means through which 
instructors and students can participate in live class discussions. The staple features of these programs are: (a) they allow for instructors and students to broadcast themselves, individually, via a webcam wherein they can see themselves and the other participants; (b) they connect the audio of participants through either an integrated phone bridge or through the use of Voice over Internet Protocol (VOIP); and (c) they provide a chat box or texting tool where participants can read and type text during a discussion (see Figure 1).

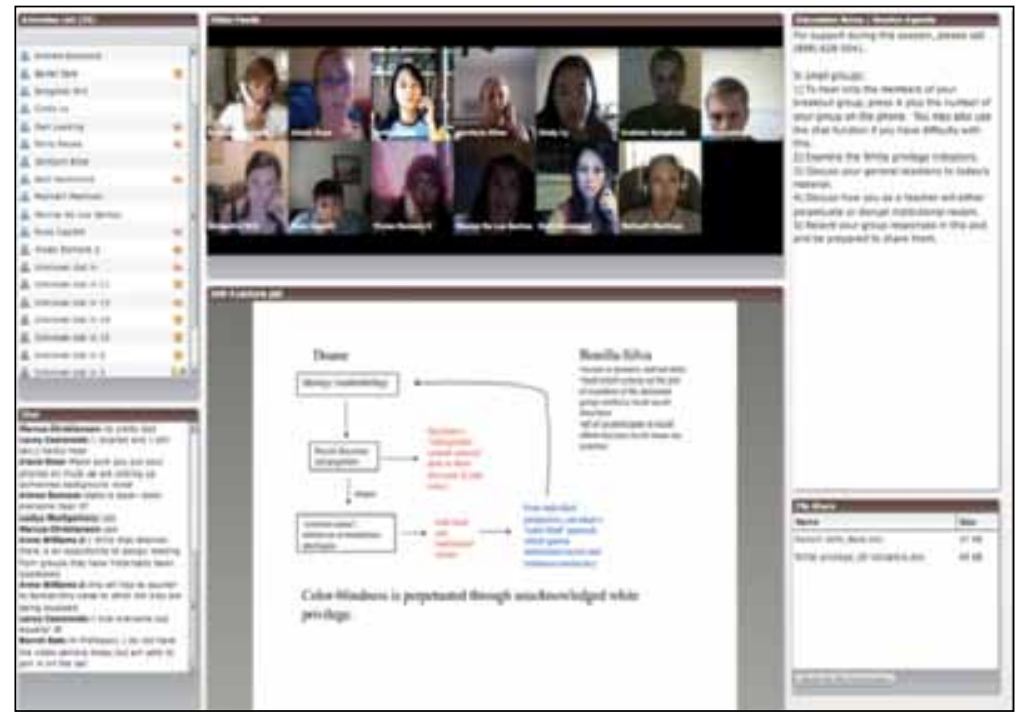

Fig. 1: Screenshot of a synchronous virtual classroom

In this environment, instructors and students exploit the distinct features of the virtual classroom much as in a brick-and-mortar classroom. They discuss readings and case studies, answer questions, respond to polls, share a desktop to demonstrate a procedure or use of other software, and engage in other traditional learning activities such as sharing experiences, and co-constructing knowledge, all within a group of 12-15 participants.

We began teaching in this environment with some technical training, and quickly figured out that our (naive) assumption that "it would be just like teaching face to face" was incorrect in at least these five significant ways: 


\section{What We Learned}

\section{Time Feels Different Online; It Can Move Too Slowly and Too Quickly}

The first thing we all noticed was that time takes on a different life in the online world; it can seem both too short (i.e., there is so much to discuss!) and too long (the wait time after a question can seem interminable). We began with very little structure in our class sessions; sessions were brief (1 hour), and generally consisted of a few discussion questions worked in the whole group setting. We found that this short class time was not sufficient for students to interact with the content, and they simply did not have the requisite prior knowledge to be able to engage with the material with so little structure.

Our reaction to this initial attempt, however, resulted in class sessions that felt far too long. We lengthened class time, and used "pushed out" information through PowerPoint lectures. This approach, too, was lacking, in that while students had more structure, the class sessions were not engaging. Long stretches of lecture, no matter how interesting, just did not work, and it was difficult to tell, using traditional strategies, if students were engaged with the content. A student staring intently at her monitor, after all, may just as easily be staring at Facebook as at a class session.

We found a happy medium by combining short, focused "lecturettes" with structured discussions, and small group work. As Palloff and Pratt (2000) note, the online instructor must be trained "not only to use technology, but also to shift the way in which they organize and deliver material" (p. 3). Most content that might ordinarily be presented in a lecture has been filmed, intercut with video examples, edited down to about 20-minute segments at their longest, and front loaded into the asynchronous portion of the course-see tip 3 for how we now use asynchronous time. Additionally, instructors introduced short multimedia tools, like images, videos, and interactive polls. Our synchronous virtual classrooms became student centered instead of teacher centered, leaving little room for students to "check out."

\section{We Underestimated the "Cognitive Overload" of Learning to Teach Online and Its Impact on Instructor Self-confidence}

Earlier research has flagged the use of the technology as a stumbling block for instructors (Berge, 1998; Palloff \& Pratt, 2000; Valentine, 2002); much of the technology being shopped around to teachers is not as easy to use as it looks. Surveys and interviews with our instructors before and after a semester of teaching 
confirmed this well-documented anxiety about becoming adroit with the tools. As in a traditional classroom, any tool an instructor wants to use needs to be prepped ahead of time, including the technology that brings the tool into the room. If the instructor begins a virtual class session without having adequately prepared all of her tools and the classroom itself, or if the instructor has not spent an appropriate amount of time familiarizing herself with the technology, then a significant amount of class time can become "dead air," which can decrease engagement and result in missed content. Instructors who are not comfortable with the technology will also choose to use fewer of the available resources that can enhance their students' learning (Akdemir, 2008).

The instructor of the virtual classroom also becomes reliant on the technological preparation of her students. Particularly in the early days of a course, students may have trouble navigating the technology. The addition of "invisible" tech support in the virtual room can help triage problems but over the long term is a costly addition. Finally, while the likelihood of a traditional class having to abandon its classroom due to some catastrophe is rare, that likelihood is far greater in the virtual classroom. Servers go down, and upgrades knock out key room functions. There are "workarounds" for almost any type of technological issue that may arise; being prepared for these issues can prevent lost or poorly utilized class time.

To help us master these "workarounds," we practiced with our technology experts who came into our virtual rooms and "sabotaged" them, making tools disappear or break down so that we had to learn to fix them, but with their coaching at first-a bit like using training wheels when learning to ride a bicycle. That kind of simulation training dramatically increased our confidence in our ability to handle most snafus. To build our pedagogical skills, we watched each other teach, and practiced with each other, trying different approaches to see what captured interest. The result has been not only acceleration in our pedagogical skills but also the emergence of a collaborative, open-door culture around our own instruction.

\section{Engaging Students Requires Far More Structure Than We Expected}

Student engagement has been defined as the observable actions, positive emotions, and the critical thinking that a learner demonstrates during a learning event (Fredricks, Blumenfeld, Friedel, \& Paris, 2005). As well, Kuh (2009) suggests that engagement occurs both in-class and out-of-class, with in-class described as the academic activities in which a student participates, usually facilitated by an instructor. 
Online instructors are often asked what is the difference between engaging students in a brick-and-mortar classroom and a virtual video conferencing classroom? Fundamentally, there is no difference. Instructors still utilize direct instruction, whole class and small group discussions, student-led presentations, and the use of multimedia such as presentation tools, video, and audio. However, because all participants in the synchronous virtual classroom are portrayed from the shoulders up, reading body language, watching students take notes, or being able to converse with a student one on one as a teacher would in a brick-and-mortar setting were not easily transferable to the virtual classroom. Therefore, how instructors engage students and the type of engagement strategies they use must be more tightly structured than in the typical classroom.

We developed several strategies that allow us to get students involved in the discussion, help them think critically, and create an environment that builds positive feelings about the experience. Two of them include the use of online polling and the chat box.

The polling feature allows an instructor to write true/false, multiple-choice, or Likert-scale questions. Stowell and Nelson (2007) found that with traditional response approaches such as hand-raising or the use of response paddles, participants are reluctant to participate because they do not want people to know if they got an answer wrong. With the use of online polling, anonymity is maintained and an instructor can see whether or not students are participating based on the number of students in the class and the number of responses collected. In this regard, an instructor can observe students engaging when they select a response.

We have used polling as an icebreaker to a class discussion, as an informal/ formative assessment tool, and to gauge students' stances on certain issues related to education, among other uses. Our typical practice involves getting students to discuss their responses, which inevitably gets other students involved by either articulating their responses or responding to those of a classmate. Moreover, when questions are connected to the readings for the week, we are able to assess, informally, students' cognitive engagement with the material, that is, how critically they are developing conceptual understanding.

In conjunction with polling is the use of the chat box during class discussion. Most video conferencing software enables participants to interact via text or what is often called instant messaging. Since the norm is to have one person speaking at a time, traditional class settings require that an instructor remember the 
order in which students raised their hands, which is often overwhelming. Moreover, students may or may not feel inclined to write a note or question on paper and then later ask it or share the comment, thus an opportunity to observe student engagement is lost. However, with the use of chat, we have been able to not only promote the use of the chat as a thought or question holder, but also actually as a place to refer to during discussion.

In a dynamic discussion, it can be challenging for a student to listen, write, and think at the same time. Furthermore, students dread the all too familiar "shoot! I forgot what I was going to say" when too much time has passed before they are called upon to speak. By making a verbal reference to the chat box during our facilitation of a class a standard practice, students not only value it as a tool of discourse, but also have utilized it in ways we never anticipated. Students have posted links to websites, YouTube, articles, and other Internet resources that can be shared with the class. They have also posed their own questions that in turn foster cognitive engagement among their peers and reflect their emotional connection to the topic. Lastly, the chat serves as a transcript of the learning event-a histogram of sorts-that students can use as a study tool, extending their engagement with the content beyond class discussion.

\section{The "Out of Class" Experience Is a Critical Partner to the Synchronous Class}

Once we realized the learning benefit to rethinking the production and placement of what used to be lecture-based material (see \#1, above), we completely rethought the use of out-of-class work. The asynchronous world became a jewel of a resource to us. We "flipped," that is we front loaded much of the fact-based learning into this environment through the use of tools like Voicethread, Screenr, Popplet, and customized video/lectures. Instead of using precious "live" class time lecturing, we scripted short lecturettes of essential points, embellished them with animation, and intercut them with videoed examples. We asked students to provide commentary on the reading and on each other's work through Voicethread, and demonstrate a particular skill through Screenr or short videos they filmed with their smart phones. All of this material was experienced before each live session.

As a result, the synchronous class experience changed. After viewing any required asynchronous materials, students spend the majority of their synchronous class time in collaborative "break out" groups, facilitated by the instructor, who jumps from room to room. These groups bring their findings back to the larger group, 
leading to whole group discussions of the content. We find we are able to move deeper into material more quickly, and move further with content and skill building than we do in the brick-and-mortar classes, as a result of this partnership between the synchronous and asynchronous environments. Not surprisingly, this "discovery" is affirmed by the USDOE report's (2010) finding that blended instruction (here they meant asynchronous and traditional face-to-face) produces greater learning gains than either modality alone. The impact has been so significant on our faculty that a number of our brick-and-mortar classes are moving to supplement or "flip" their use of live class time with the introduction of asynchronous resources.

\section{We Got to Know Our Students, and They Us, Far Better Than We Imagined}

One of our deepest fears was that the experience of teaching online would be impersonal. After all, many of us got in to teaching because of the opportunity to build relationships that might make a difference. A great surprise, then, was how quickly and easily we got to know our students. Because the platform included a social networking function, with individual profiles and walls à la Facebook, we were able to read about our students' interests, favorite books, and so forth before class began, and connect with them. The more we shared about our own interests, the more we reached out to our students, the more they responded in kind, eager to get to know us, each other, and the university. When commencement arrived, it was delightful to watch students, who had become fast friends, gleefully meet each other face to face for the first time. This lesson was perhaps the most heartwarming of allnot only could the technology help us facilitate learning in a mechanical way, but it could also help us build the relationships that are so critical to effective instruction.

\section{Conclusion}

If there is one lesson to be learned from our venture into the online, hybrid world, it is this: the most important element is not the tools, which is what online conditions are, but rather the quality of the instruction. When we struggled to engage our students in the first 10 minutes, the fault was not with the tool (the virtual classroom) but with the instructors who needed to figure out how to activate the same principles of good teaching within that new condition, and then learn the strengths of that new condition so that it could be exploited. The elements of good teaching, understanding one's content and one's learners, using data to know where your 
learners are and adapting your instruction accordingly, apply regardless of the condition or tool being used. Online tools, like any tool, cannot alone produce learning gains; they have to be employed thoughtfully, purposefully, and skillfully to achieve their maximum potential.

\section{References}

Akdemir, O. (2008). Teaching in online courses: Experiences of instructional technology faculty members. Turkish Online Journal of Distance Education--TOJDE, 9(2), 97-108.

Allen, E., \& Seaman, J. (2011). Going the distance -- Online education in the United States, 2011. Retrieved from http://www.online learningsurvey.com/reports/goingthe distance.pdf

Anderson, T., Rourke, L., Garrison, D. R., \& Archer, W. (2001). Assessing teaching presence in a computer conferencing context. Journal of Asynchronous Learning Networks, 5(2), 1-17.

Berge, Z. L. (1998). Barriers to online teaching in post-secondary institutions: Can policy fix it? Journal of Distance Learning Administration, 1(2).

Chong, H. (2012). Perception and use of instructional technology: Teacher candidates as adopters of innovation (Unpublished dissertation). University of Southern California, Los Angeles.

Fredricks, J. A., Blumenfeld, P., Friedel, J., \& Paris, A. (2005). School engagement. In K. A. Moore \& L. Lippman (Eds.), What do children need to flourish? Conceptualizing and measuring indicators of positive development (pp. 305-321). New York: Springer.
Kuh, G.D. (2009). What student affairs professionals need to know about student engagement. Journal of College Student Development 50, 683-706.

Palloff, R. M., \& Pratt, K. (2000). Making the transition: Helping teachers to teach online. Unpublished paper presented at EDUCAUSE: Thinking it through. Nashville, TN.

Picciano, A.G., \& Seaman, J. (2008-2009). K-12 Online Learning: A 2008 Follow-Up of the Survey of U.S. School District Administrators. Needham, MA: The Sloan Consortium.

Stowell, J. R., \& Nelson, J. M. (2007). Benefits of electronic audience response systems on student participation, learning, and emotion. Teaching of Psychology, 34(4), 253-258.

U.S. Department of Education. (2010). Evaluation of evidence-based practices in online learning: A meta-analysis and review of online learning studies. Washington, DC: Means, B.; Toyama, Y.; Murphy, R.; Bakia, M.; \& Jones, K.

Valentine, D. (2002, October 9). Distance learning: Promises, problems, and possibilities. Online Journal of Distance Learning Administration, 5(3). 


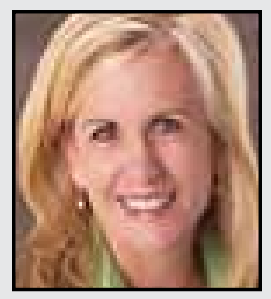

Kimberly Ferrario is an Assistant Professor of clinical education at the Rossier School of Education at the University of Southern California. Currently, Dr. Ferrario teaches full time for the online Master of Arts in Teaching program at USC. Her research interests include sociocultural aspects of language and literacy development, assessment, teacher professional development, classroom discourse, and writing pedagogy. Dr. Ferrario has 20 years combined experience teaching for a school district in the North Bay Area in California at the elementary level, as a reading specialist, and as a literacy coach/coordinator of professional development in literacy for $\mathrm{K}-12$ teachers.

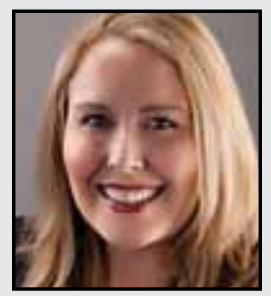

Corinne Hyde is an Assistant Professor of clinical education at the Rossier School of Education at the University of Southern California. Dr. Hyde has a variety of experience in the field of education, including classroom teaching, special education, community education, and educational administration. She currently resides in St. Gabriel, Louisiana and was the first full-time faculty member in the online Master of Arts in Teaching program to be fully off-site, teaching through the MAT online program's virtual campus. Dr. Hyde is currently researching the process of transitioning to teaching online among postsecondary faculty and student engagement in virtual classrooms.

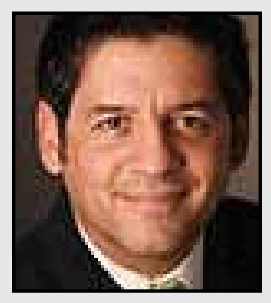

Brandon Martinez is an Assistant Professor of clinical education in the Rossier School of Education. Dr. Martinez teaches learning theories and secondary English language arts pedagogy in the MAT online program both on campus and online, and teaches in the Ed.D. program. His research interests include the use of educational technology in curriculum design, instruction, teacher preparation, student learning, and teacher training in educational technology. Prior to joining USC, Martinez taught high school English for eight years and was an assistant principal for three years. 


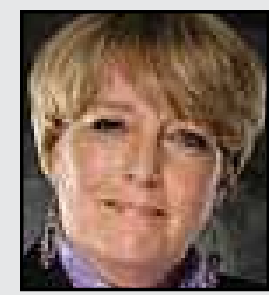

Melora Sundt is Vice Dean for Academic Programs and Professor of Clinical Education in the Rossier School of Education at the University of Southern California. In this capacity, she oversees the degree programs, admissions and student services, and through the Associate Dean supervises program directors. Dr. Sundt specializes in the areas of online learning and instruction, creativity and innovation in higher education, diversity issues, and violence prevention on college campuses. Dr. Sundt chaired the design teams that created the MAT@USC program and the Global Executive EdD., and teaches in the master's, MAT, Global Executive EdD, and on-campus EdD programs. 